\title{
Identification of Carriers of a Variant Plasma Prealbumin (Transthyretin) Associated with Familial Amyloidotic Polyneuropathy Type I
}

\author{
Merrill D. Benson and Francis E. Dwulet \\ Rheumatology Division, Richard L. Roudebush Veterans Administration Medical Center, Departments of Medicine and Biochemistry, \\ Indiana University School of Medicine, Indianapolis, Indiana 46223
}

\begin{abstract}
A method is described for detecting carriers of a variant plasma prealbumin that is associated with familial amyloidotic polyneuropathy (FAP) type I. It is based on the finding of an extra methionine in the variant prealbumin, at position $\mathbf{3 0}$ from the amino terminus. Since normal prealbumin has only one methionine (position 13), treatment with cyanogen bromide (CNBr), which cleaves only at methionines, results in two peptides. CNBr treatment of the variant prealbumin gives three peptides. The extra peptide can then be detected in two ways: by HPLC using a reverse phase $\mathrm{C} 18$ column, and by sequential Edman degradation. Each method can detect as little as $1 \%$ variant prealbumin in isolated plasma prealbumin, and therefore, can identify carriers of the gene for the variant protein. Since FAP type I usually is not manifest until after the childbearing years, this method to identify carriers of the gene offers a new approach for genetic counseling of families with this disease. To date, kindreds with hereditary amyloidosis that could benefit from these studies include those with FAP type I of Swedish, Japanese, and Portuguese origins.
\end{abstract}

\section{Introduction}

We recently described a thyroxine-binding plasma prealbumin (transthyretin) variant that was isolated from amyloid fibrils in hereditary amyloidosis of Swedish origin (1). This variant protein has a single amino acid change, a methionine for valine at position 30 from the amino terminus. A similar finding was reported for the subunit protein of hereditary amyloid in Japan and also for hereditary amyloid from Portugal $(2,3)$.

In the amyloid patients of Swedish origin, both normal and variant forms of prealbumin are found in the amyloid fibrils and in the plasma of affected individuals (4). Since it is likely that circulating prealbumin is the precursor of the amyloid fibril subunit protein, it is logical that the variant prealbumin would be present in the plasma of individuals before they reach the age of usual onset of amyloidosis symptoms. To identify the carriers of this genetic variant, we devised a method for detecting this particular protein in the plasma of children of affected individuals. It is based on cleaving the prealbumin proteins with cyanogen bromide

Address reprint requests to Dr. Benson, Richard L. Roudebush Veterans Administration Medical Center, Indianapolis, IN 46202.

Received for publication 25 June 1984 and in revised form 24 August 1984

The Journal of Clinical Investigation, Inc.

Volume 75 , January $1985,71-75$
$(\mathrm{CNBr})^{1}$ and analyzing the number of resulting peptides. Since the variant prealbumin has an additional methionine, cleavage with $\mathrm{CNBr}$ gives a characteristic peptide that is not produced by $\mathrm{CNBr}$ treatment of normal prealbumin. The advantage of diagnosing this dominant condition before the childbearing age is obvious.

\section{Methods}

Subjects. Two offspring from each of two brothers with hereditary amyloidosis were studied (5). This kindred of Swedish origin first described in 1975 (Fig. 1) is afflicted with typical familial amyloidotic polyneuropathy (FAP) type I, with death usually resulting from renal failure. Amyloid fibrils isolated from renal tissues of each parent have been shown to contain the variant prealbumin containing two methionines per subunit protein $(1,6)$. The four subjects who volunteered their plasma for these studies ranged in age from 22 to $32 \mathrm{yr}$. None has manifested symptoms of neuropathy or other organ dysfunction consistent with amyloidosis. Prealbumin was isolated from plasma by a modification of the procedure of Rask et al. (7). $100 \mathrm{ml}$ of plasma was equilibrated with $0.15 \mathrm{M} \mathrm{NaCl} / 0.02 \mathrm{M}$ Tris $\mathrm{HCl}, \mathrm{pH}$ 7.4. After removal of insoluble material, the sample was applied to a column $(2.6 \times 40 \mathrm{~cm})$ of DEAE-Sephadex A-50 (Pharmacia Fine Chemicals, Piscataway, NJ) and the proteins were eluted with a linear gradient of $\mathrm{NaCl}$ from 0.15 to $0.45 \mathrm{M}$ (total vol, 2 liters). The prealbumin fraction was pooled, concentrated, reequilibrated with the starting buffer, and applied to a column $(2.6 \times 13 \mathrm{~cm})$ of Affi-gel Blue (Bio-Rad Laboratories, Richmond, CA). Final purification of the prealbumin was achieved by chromatography on a column $(2.6 \times 95 \mathrm{~cm})$ of AcA 34 (LKB Instruments, Inc., Gaithersburg, MD).

Prealbumin (3 mg) was dissolved in $1 \mathrm{ml}$ of deoxygenated $70 \%$ formic acid to which was added an equal weight of $\mathrm{CNBr}$ (Eastman Laboratory and Specialty Chemicals, Rochester, NY). The mixture was kept in the dark at room temperature for $24 \mathrm{~h}$ with constant stirring (8). The samples were then diluted with $10 \mathrm{vol}$ of distilled water and lyophilized.

$\mathrm{CNBr}$-cleaved prealbumin was fractionated by high-performance liquid chromatography (HPLC) on an RPP column $(0.45 \times 25 \mathrm{~cm}$; SynChrom, Inc., Linden, IN). Peptides were eluted using a gradient of 2-propanol and identified by absorbance at $215 \mathrm{~nm}$.

Automated sequence analyses were carried out on an automatic sequenator (890C; Beckman Instruments, Inc., Fullerton, CA) using the 0.1-M quadrol program (121078). For peptides, $3 \mathrm{mg}$ of Polybrene was added with each sample, and one cycle in which phenylisothiocyanate was not added was carried out to remove impurities. To the anilinothiazolinone derivatives obtained from the sequenator was added $15 \mathrm{nmol}$ of norleucylphenylthiohydantoin as an internal standard. All samples were converted to the phenylthiohydantoin derivative by heating at $80^{\circ} \mathrm{C}$ in $1 \mathrm{M} \mathrm{HCl}$ for $10 \mathrm{~min}$. The phenylthiohydantoin

1. Abbreviations used in this paper: $\mathrm{CB} 1$, cyanogen bromide peak 1 ; CB2, cyanogen bromide peak 2; CBV1, cyanogen bromide variant peak 1; CBV2, cyanogen bromide variant peak $2 ; \mathrm{CNBr}$, cyanogen bromide; FAP, familial amyloidotic polyneuropathy; HPLC, highperformance liquid chromatography. 


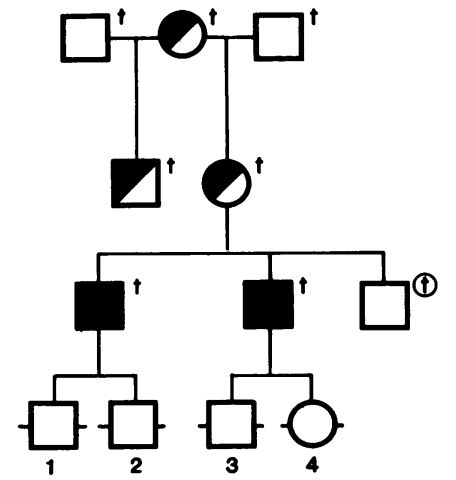

Figure 1. Kindred with FAP type I showing the four individuals whose prealbumin was studied. Key: $n$, affected; $\bullet$, presumed affected; $\uparrow$, deceased $\neg-$, before usual age of onset; $\odot$, died before usual age of onset.

amino acids were identified by chromatography on a gradient HPLC system (Waters Instruments, Inc., Milford, MA) equipped with a column (Ultrasphere $\mathrm{C}-18,0.46 \times 25 \mathrm{~cm}$; Altex Scientific, Inc., Berkeley, CA) and a column heater (Eldex Laboratories, Inc., Menlo Park, CA). Peaks were identified by their absolute and relative (to the norleucine standard) retention times. Peak identification and quantitation were carried out on a reporting integrator (3390A; HewlettPackard Co., Palo Alto, CA). The chromatography conditions used were a minor modification of the procedure of Zimmerman et al. (9). Amino acid derivatives not clearly identified by this method were reconverted to the free amino acid by hydrolysis at reduced pressure in $5.7 \mathrm{M} \mathrm{HCl} / 0.1 \% \mathrm{SnCl}_{2}$ at $150^{\circ} \mathrm{C}$ for $12 \mathrm{~h}$ and identified on an amino acid analyzer (119C; Beckman).

\section{Results}

The plasma concentrations of prealbumin for each of the four subjects of this study are listed in Table I with the yields from $100 \mathrm{ml}$ of plasma from each. The yield of $35-50 \%$ of theoretical for the three-stage procedure of prealbumin isolation is more than adequate to give the amount of protein from $100 \mathrm{ml}$ of plasma that is necessary for the chemical analyses. As little as $10 \mathrm{ml}$ of plasma would suffice.

Separation of CNBr peptides by HPLC gave two easily distinguished patterns. Pattern one, which is identical to $\mathrm{CNBr}$ degraded normal prealbumin from an individual without a family history of amyloidosis, shows two major peptides (Fig. $2 A$ ). This pattern was seen with two of the prealbumin preparations (subjects 2 and 3). Pattern two (Fig. 2 B) was seen with the other two individuals ( 1 and 4 ) and showed four peptides. This is consistent with those prealbumin preparations containing a mixture of normal prealbumin, which gives two peptides, and the variant prealbumin, which has two methionines and gives three peptides (including the normal amino terminal peptide).

Table I. Isolation of Prealbumin from Plasma

\begin{tabular}{llll}
\hline Patient & $\begin{array}{l}\text { Plasma prealbumin } \\
\text { concentration* }\end{array}$ & $\begin{array}{l}\text { Yield from } 100 \mathrm{ml} \\
\text { plasma }\end{array}$ & $\begin{array}{l}\text { Theoretical } \\
\text { yield }\end{array}$ \\
\hline & $m g / d l$ & $m g$ & $\%$ \\
1 & 22.7 & 8 & 35 \\
2 & 25.0 & 13 & 52 \\
3 & 32.0 & 13 & 40 \\
4 & 21.0 & 8 & 38
\end{tabular}

* Determined by radial immunodiffusion assay (Calbiochem Partigen).
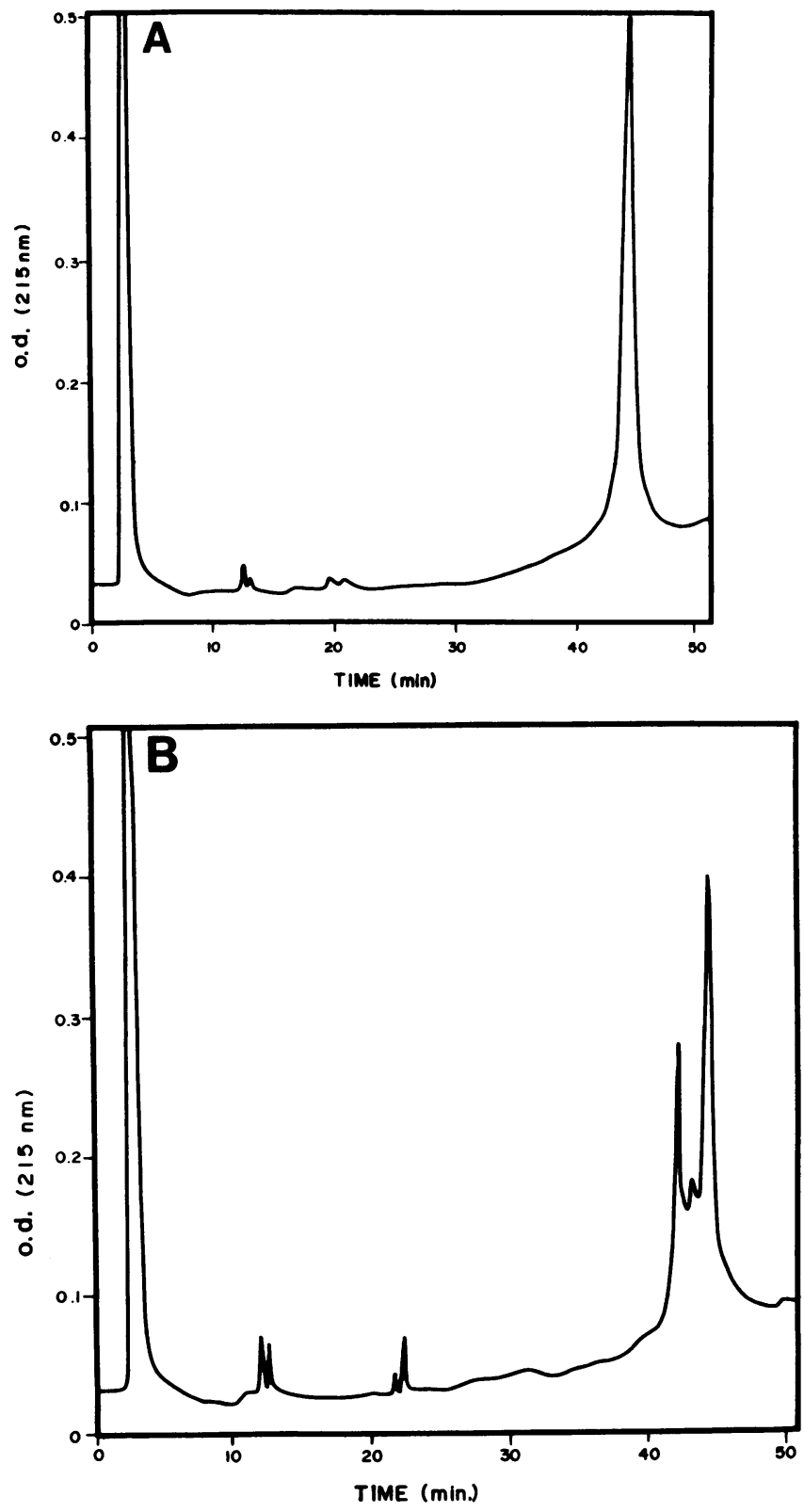

Figure 2. (A) Representative HPLC profile of $\mathrm{CNBr}$ peptides of prealbumin from subjects 2 and 3 and a nonamyloid control subject. The small peaks at 12 min are the $\mathrm{NH}_{2}$-terminal peptide (CB1). The large peak at $43-45 \mathrm{~min}$ is the large peptide from positions 14-127 (CB2). The minor peaks at 20 min were nonpeptide in nature. $(B)$ HPLC profile of $\mathrm{CNBr}$ peptides of prealbumin from subjects 1 and 4 . The peaks at 22-23 min are the peptide from positions $14-30$ (CBV1). The peak at $42 \mathrm{~min}$ is the peptide from positions 31-127 (CBV2).

All the peptides from one of the prealbumins showing pattern two (Fig. $2 B$ ) were isolated and subjected to sequence analysis. $\mathrm{CNBr}$ peak 1 (CB1) gave a sequence Gly-Pro-Thr, which identifies it as the amino terminal peptide. CNBr peak 2 (CB2) gave a sequence of Val-Lys-Val, which is consistent with the normal prealbumin sequence from positions 14-127. CNBr variant peak 1 (CBV1) also gave a sequence of Val-LysVal but the amino acid analysis shows that this peptide represents positions $14-30$ of the aberrant protein. $\mathrm{CNBr}$ 
Table II. Sequential Degradation of Isolated Peptides from $\mathrm{CNBr}$-treated Prealbumin

\begin{tabular}{llllll}
\hline Peptide & $\begin{array}{l}\text { Sample } \\
\text { applied }\end{array}$ & Step 1 & Step 2 & Step 3 & $\begin{array}{c}\text { Assigned } \\
\text { sequence }\end{array}$ \\
\hline & $n m o l$ & & & & \\
CB1 & 6 & Gly (3)* & Pro (1) & Thr (1) & $1-13$ \\
CB2 & 9 & Val (8) & Lys (6) & Val (6) & $14-127$ \\
CBV1 & 7 & Val (5) & Lys (3) & Val (4) & $14-30$ \\
CBV2 & 6 & His (2) & Val (5) & Phe (5) & $30-127$ \\
& & & & & \\
\hline
\end{tabular}

* Yield in nanomoles.

variant peak 2 (CBV2) gave the sequence His-Val-Phe, which is consistent with it being derived from the cleavage at methionine in position $\mathbf{3 0}$ of the variant prealbumin. Table II shows the data for the first three residues from sequence analysis of each isolated peptide. Each peptide gave a clean sequence with no ambiguous assignments.

The data for automatic sequence degradation of each of the nonfractionated $\mathrm{CNBr}$-degraded prealbumin preparations from the four individuals are shown in Table III. In two cases (2 and 3), the data are consistent with the simultaneous
Table III. Sequential Degradation of CNBr-treated Prealbumin

\begin{tabular}{lllll}
\hline Patient & Step 1 & Step 2 & Step 3 & Step 4 \\
\hline 1 & Gly (33)* & Pro (10) & Thr (6) & Gly (20) \\
& Val (49) & Lys (37) & Val (45) & $\begin{array}{l}\text { Leu (41) } \\
\end{array}$ \\
His (15) & Val (24) & Phe (14) & Arg (4) \\
& Gly (51) & Pro (30) & Thr (10) & Gly (52) \\
& Val (58) & Lys (58) & Val (61) & Leu (60) \\
& Gly (50) & Pro (32) & Thr (13) & Gly (41) \\
& Val (57) & Lys (64) & Val (58) & Leu (58) \\
& & & & \\
4 & Gly (41) & Pro (16) & Thr (4) & Gly (27) \\
& Val (39) & Lys (32) & Val (35) & Leu (27) \\
& His (11) & Val (22) & Phe (10) & Arg (5) \\
& & & & \\
\hline
\end{tabular}

* Yield in nanomoles.

degradation of two peptide chains and are identical to data obtained with $\mathrm{CNBr}$-degraded normal prealbumin. In the other two prealbumin preparations ( 1 and 4 ), the data are consistent with the simultaneous sequential degradation of three peptide chains (Fig. 3).

(A) Prealbumin Sequence

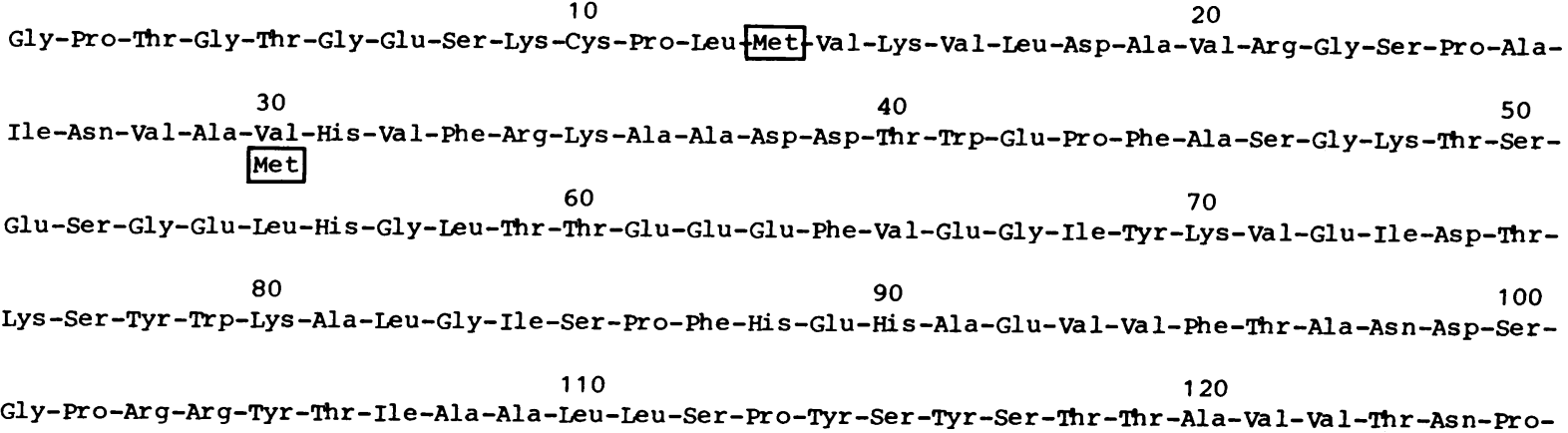

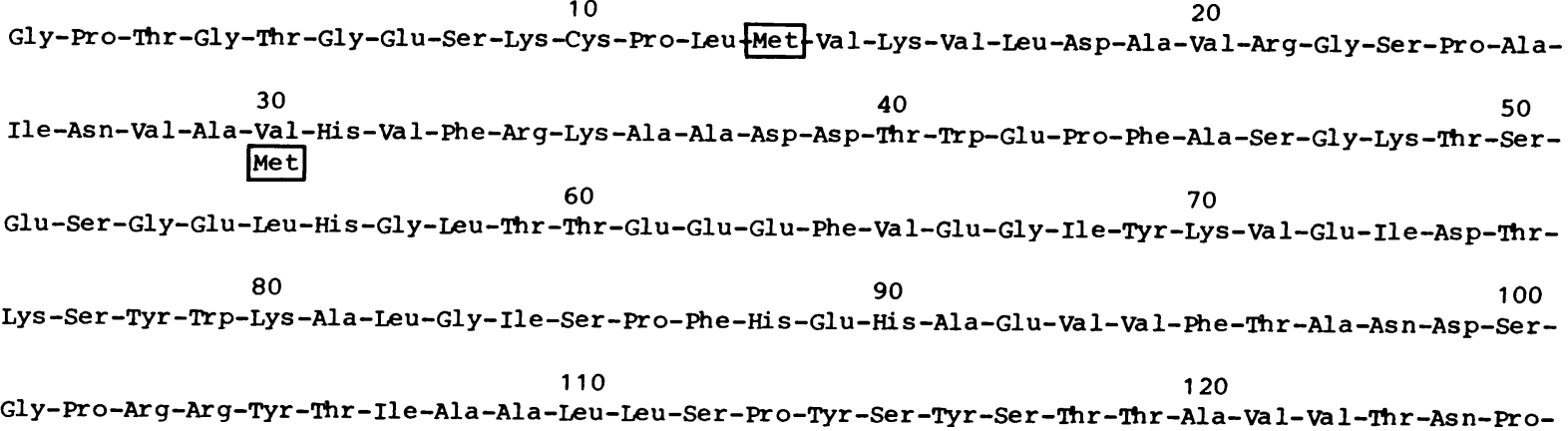

Lys-Glu

(B) CNBr Peptides of Normal prealbumin

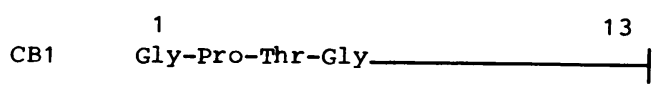

CB2

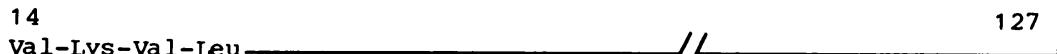

CNBr Peptides of Variant prealbumin

CB1

Gly-Pro-Thr-Gly

CBV1

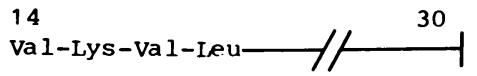

CBV2

31

His-Val-Phe-Arg-
127

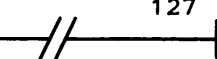

Figure 3. (A) Amino acid sequence of normal (10) and the variant prealbumin showing Val/Met polymorphism at position 30 . (B) Graphic representation of peptides generated by $\mathrm{CNBr}$ cleavage of normal and variant prealbumin. The first four residues of each peptide are shown to explain the amino acid sequence data in Table III. 
To evaluate the sensitivity of the HPLC method of identifying the variant prealbumin, mixing experiments using normal and variant prealbumin preparations were done. From the sequenator yield data (Table III), it was determined that the prealbumin preparation from subject 4 contained $35 \%$ variant prealbumin. This is consistent with the yields of normal and variant tryptic peptides from the prealbumin of an individual with FAP type I (1). A CNBr-treated preparation of prealbumin from subject 4 was serially diluted with known amounts of $\mathrm{CNBr}$-cleaved normal prealbumin to generate mixtures with decreasing concentrations of the two variant peptides (CBV1 and CBV2). Analysis of each dilution by HPLC revealed that the peak at 42 min representing CBV2 (Fig. $2 B$ ) could be identified in samples having as little as $1 \%$ variant peptide.

\section{Discussion}

In all cases of autosomal dominant heredofamilial amyloidosis that have been studied biochemically, prealbumin has been found to be the subunit protein of the fibril. This includes two Swedish kindreds $(6,11)$, a Japanese kindred (2), Portuguese patients with FAP type $I(3,12)$, the Indiana-Swiss kindred with FAP type II (13), and a lone Israeli with an unclassified form of amyloidosis (14). It is known that the prealbumin from the Swedish family that we have studied is a variant having a methionine substitution for the valine at position $\mathbf{3 0}$ from the amino terminus (4). The same finding has been reported for amyloid from one Japanese family (2), and a recent study shows the same variant prealbumin in the Portuguese amyloid (15). The prealbumin isolated from amyloid of the one Israeli patient had a glycine-threonine interchange at position 49 of the molecule (14). Both the Swedish and Israeli amyloid proteins have been completely sequenced and shown to have just one amino acid substitution each. While the complete sequence of the Portuguese amyloid protein has not been reported, there are no data to suggest that it has more than the one substitution (15). Preliminary studies on amyloid from the Indiana-Swiss kindred with FAP type II show that this type of amyloid does not contain the variant prealbumin with an extra methionine residue.

Since all of the autosomal dominant heredofamilial amyloidoses that have been described become clinically apparent after the start of the reproductive years, the only assured way that an individual at risk for developing the disease can prevent passage of the aberrant gene to his/her children has been to elect not to have children. This is not a viable alternative to many individuals. In addition, increased dissemination of aberrant prealbumin genes has become obvious from the studies of several kindreds. While high infant mortality and early death for patients with peripheral neuropathy from infected leg ulcers markedly decreased the size of reproductive family units in the 19th and early 20th centuries, modern medicine has increased the likelihood that the amyloid gene will be preserved in an increasing number of families. This has been balanced somewhat by the trend toward smaller family size.

To prevent the transmission of the aberrant prealbumin genes, but at the same time allow the having of unaffected offspring, would require a genetic probe. This new methodology would allow prenatal identification of carriers of the aberrant genes, and appropriate family planning could be obtained if desired. This methodology, however, has not yet been developed for identification of prealbumin genes. Until genetic analysis can be done, a method for identifying carriers of abnormal prealbumin genes, which are associated with systemic amyloidosis, would allow those individuals who do not have the aberrant gene to plan their families without worry of amyloidosis. In addition, it would allow those individuals who do have the aberrant prealbumin to make a conscious decision whether to risk passing the gene on to the next generation. Such an option is readily available for those kindreds having the aberrant prealbumin with an extra methionine residue.

Since there seems to be a wide variation in the concentration of the variant prealbumin in plasma from individuals of different kindreds, studies were done to evaluate the sensitivity of the identification methods outlined above. These showed that as little as $1 \%$ variant prealbumin could be detected by HPLC. While we found 30\% variant prealbumin in the plasma of the Swedish patients (4), Sariava et al. reported data suggesting $<20 \%$ abnormal prealbumin in plasma from Portuguese patients with amyloidosis (15). Since their plasma preparations were pooled from several patients, it is possible that some individuals had significantly higher or lower amounts of the variant prealbumin. Thus far, we have not found $>50 \%$ or $<20 \%$ variant prealbumin in any subject with this trait. The lower variant prealbumin concentration could be due to increased degradation or decreased synthesis. To date we have no data on the metabolic turnover of the prealbumin. Total plasma prealbumin concentrations were significantly decreased in individuals with both FAP type I and type II, but the mechanisms leading to this finding have not been investigated $(3,13)$. It is possible that there is decreased expression of the variant prealbumin gene. This is true for other codominant alleles and may involve regulatory genes or other modulating mechanisms of gene expression. In this respect we do not yet have chronological data on expression of the variant gene. We have shown that the variant prealbumin is present in one subject by age $22 \mathrm{yr}$, even though the youngest member of this kindred to develop clinical evidence of amyloidosis was 35 yr old (5). Normal prealbumin plasma levels have been shown to increase over the first 20-30 yr of life but may be lowered in cystic fibrosis and other conditions giving poor nutrition (16). Whether the abnormal prealbumin is present in the plasma of carriers before adulthood could not be determined in this study because of lack of suitable subjects. In any case, it seems that the variant prealbumin is present many years before clinical expression of disease.

The mixing experiments of normal and abnormal prealbumin were done for two reasons. First, if there is a lower degree of variant prealbumin gene expression at younger ages, the ability to detect as little as $1 \%$ variant form could lead to earlier detection of carriers. Second, there are a number of kindreds with this genetic defect on diverse genetic backgrounds (Japanese, Portuguese, Swedish), and a wide variation in gene expression may be found. Therefore, the ability to detect low levels of the variant gene product may become important for genetic studies in other kindreds.

In addition, since $<1 \mathrm{mg}$ of prealbumin is required for the $\mathrm{CNBr}$ degradation, the complete analysis can be done with as little as $10 \mathrm{ml}$ of plasma. Recent reviews documented several hundred families with FAP type I in Portugal (17), and 
additional large kindreds in Japan (18). Application of this methodology, which is very sensitive and relatively easy, to the Japanese and Portuguese families with amyloidosis that have the same genetic defect, could have major impact on genetic counseling. In addition, the ability to identify carriers long before the onset of symptoms may allow the study of possible modulating factors that may play a role in the differences seen in expression (particularly age of onset) of the disease.

\section{Acknowledgments}

The authors wish to thank Francis Kenny and Marilyn Smith for technical assistance and Patricia Rusie for secretarial assistance.

This work was supported by Veterans Administration Medical Research (MRIS 583-0888), and grants from RR-00750 (GCRC), United States Public Health Service, National Institute of Arthritis, Metabolism and Digestive Diseases (AM 20582 and AM 7448), The Arthritis Foundation, and The Grace M. Showalter Foundation.

\section{References}

1. Dwulet, F. E., and M. D. Benson. 1984. Primary structure of an amyloid prealbumin and its plasma precursor in a heredofamilial polyneuropathy of Swedish origin. Proc. Natl. Acad. Sci. USA. 81:694698.

2. Tawara, S., M. Nakazato, K. Kangawa, H. Matsuo, and S. Araki. 1983. Identification of amyloid prealbumin variant in familial amyloidotic polyneuropathy (Japanese Type). Biochem. Biophys. Res. Commun. 116:880-888.

3. Saraiva, M. J. M., P. P. Costa, and D. S. Goodman. 1983. Studies on plasma transthyretin (prealbumin) in familial amyloidotic polyneuropathy, Portuguese type. J. Lab. Clin. Med. 102:590-603.

4. Dwulet, F. E., and M. D. Benson. 1983. Polymorphism of human plasma thyroxine binding prealbumin. Biochem. Biophys. Res. Commun. 114:657-662.

5. Benson, M. D., and A. S. Cohen. 1977. Generalized amyloid in a family of Swedish origin. A study of $\mathbf{4 2 6}$ family members in seven generations of a new kinship with neuropathy, nephropathy and central nervous system involvement. Ann. Intern. Med. 86:419-424.
6. Benson, M. D. 1981. Partial amino acid sequence homology between an heredofamilial amyloid protein and human plasma prealbumin. J. Clin. Invest. 67:1035-1041.

7. Rask, L., P. A. Peterson, and S. F. Nilsson. 1971. The subunit structure of human thyroxine-binding prealbumin. J. Biol. Chem. 246:6087-6097.

8. Gross, E. 1967. The cyanogen bromide reaction. Methods Enzymol. 11:238-255.

9. Zimmerman, C. L., A. Appella, and J. J. Pisano. 1977. Separation of amino acid phenylthiohydantoins by high performance liquid chromatography. Anal. Biochem. 77:569-573.

10. Kanda, Y., D. S. Goodman, R. E. Canfield, and F. J. Morgan. 1974. The amino acid sequence of human plasma prealbumin. J. Biol. Chem. 249:6796-6805.

11. Skinner, M., and A. S. Cohen. 1981. The prealbumin nature of the amyloid protein in familial amyloid polyneuropathy (FAP): Swedish variety. Biochem. Biophys. Res. Commun. 99:1326-1332.

12. Costa, P. P., A. S. Figueira, and F. R. Bravo. 1978. Amyloid fibril protein related to prealbumin in familial amyloidotic polyneuropathy. Proc. Natl. Acad. Sci. USA. 75:4499-4503.

13. Benson, M. D., and F. E. Dwulet. 1983. Prealbumin and retinol binding protein serum concentrations in the Indiana type hereditary amyloidosis. Arthritis Rheum. 26:1493-1498.

14. Pras, M., E. C. Franklin, F. Prelli, and B. Frangione. 1981. A variant of prealbumin from amyloid fibrils in familial polyneuropathy of Jewish origin. J. Exp. Med. 154:989-993.

15. Saraiva, M. J. M., S. Birken, P. P. Costa, and D. S. Goodman. 1984. Amyloid fibril protein in familial amyloidotic polyneuropathy, Portuguese type. J. Clin. Invest. 74:104-119.

16. Smith, F. R., B. A. Underwood, C. R. Denning, A. Varma, and D. S. Goodman. 1972. Depressed plasma retinol-binding protein levels in cystic fibrosis. J. Lab. Clin. Med. 80:423-433.

17. Coutinho, P., A. M. da Silva, J. L. Lima, and A. R. Barbosa. 1980. Forty years of experience with Type I amyloid neuropathy. Review of 483 cases. In Amyloid and Amyloidosis. G. G. Glenner, P. P. Costa, and F. Freitas, editors. Excerpta Medica, Amsterdam. 8898.

18. Araki, S., T. Kurihara, S. Tawara, and T. Kuribayashi. 1980. Familial amyloidotic polyneuropathy in Japanese. Clinical, pathophysiological, biochemical, and therapeutic studies. In Amyloid and Amyloidosis. G. G. Glenner, P. P. Costa, and F. Freitas, editors. Excerpta Medica, Amsterdam. 67-77. 